\title{
Arrecadação de ICMS do Estado do Rio de Janeiro: A elasticidade dos setores econômicos e seu uso na melhora da situação fiscal e financeira do Estado
}

\author{
Alessandra Oliveira Ribeiro (UCAM) alessandra.o.r@gmail.com \\ Francine Santana Lacerda Bezerra (UCAM) francinerj@ hotmail.com \\ Marcelo Jusan Fernandes (UCAM) marcelojusan@ gmail.com \\ Sandra Barbosa Silva de Almeida (UCAM) sandryynha@gmail.com \\ Daiane Rodrigues dos Santos (UCAM) daianesantoseco@gmail.com
}

\section{Resumo}

O trabalho busca analisar a evolução da arrecadação do Imposto de Circulação de Mercadorias e Serviços (ICMS) do Estado do Rio de Janeiro no período de 1997 a 2019. Nesta análise, discutem-se os fatores determinantes da arrecadação de ICMS, com intuito de contribuir com um incremento da arrecadação desse imposto e auxiliar na melhora da situação fiscal e financeira do Estado. A partir de modelo econométrico, são estimadas as elasticidades dos setores primário, secundário, terciário, energia, petróleo e outros em relação à arrecadação total de ICMS do Estado. A sensibilidade da receita tributária é de significativa relevância para a condução da política fiscal do Estado, sendo a elasticidade geralmente utilizada como medida de sensibilidade. A análise buscou identificar o setor da economia fluminense que deveria ter seus investimentos priorizados a fim de otimizar a arrecadação total dos impostos no estado. Os resultados indicam que todos os setores, com exceção do setor primário, apresentaram elasticidades positivas, o que significa dizer que o aumento da arrecadação de ICMS do setor tende a elevar a arrecadação total. Porém, a arrecadação do setor terciário apresentou elasticidade superior aos demais setores ao longo do período em análise, o que reflete a relevância desse setor na economia regional e serve como balizador para que o governo do estado do Rio de Janeiro priorize o setor terciário de modo a otimizar os investimentos e maximizar a arrecadação total de ICMS do estado.

Palavras-Chaves: Elasticidade; Elasticidade da Receita Tributária; ICMS. 


\section{Introdução}

Soares, Gomes e Toledo Filho (2011) definem o Imposto sobre a Circulação de Mercadorias e Serviços (ICMS) como uma das principais fontes de recursos, para compor o planejamento orçamentário dos estados e municípios, provenientes da produção e movimentação das riquezas econômicas.

De acordo com Marques Junior e Oliveira (2014), a sensibilidade da receita tributária a mudanças nas variáveis macroeconômicas é de suma importância para a condução da política fiscal, uma vez que a receita tributária é a principal fonte de recursos para os Estados e Municípios.

Como citado por Sobral (2017), o Estado do Rio de Janeiro vem passando nos últimos anos, por uma progressiva deterioração de suas contas. Arrestos judiciais, desgoverno por parte dos gestores, contribuíram para a grave situação que passa o Estado. A problemática crise financeira do governo estadual não é simplesmente o ajuste as contas públicas, mas sim como fazer isso dentro de um processo de recuperação econômica sustentado.

Em regime de recuperação fiscal desde 2017, aprovado pelo Ministério da Economia em 01/04/2017 por meio da Resolução $n^{0}$ 16, o Estado do Rio de Janeiro tem desenvolvido medidas para a volta do crescimento econômico do Estado. Conforme o relatório de monitoramento do Plano de Recuperação Fiscal (2019), o Governo Estadual está revisando os incentivos físcais concedidos, alcançando uma redução de $50 \%$ do esperado, modernizando todo o sistema de cobrança e fiscalização fazendária e alterações de alíquotas de ICMS.

Dados da Federação de Indústrias do Estado (FIRJAN) apontam que a indústria da capital fluminense apresentou recuo no volume de produção em junho (41,0 pontos), mantendo o resultado negativo observado em março (Indicador abaixo de 50 pontos indica queda e acima de 50 pontos indica aumento). Paralelamente, o nível de estoques cresceu (55,0 pontos), mas ficou acima do planejado (54,2 pontos). Os resultados da região foram inferiores ao observado no estado. Dessa forma, a Utilização da Capacidade instalada da indústria do Rio de Janeiro seguiu em junho (55,0\%) abaixo da média histórica do indicador $(63,8 \%)$.

O objetivo do trabalho é medir as elasticidades dos setores da economia na arrecadação total do ICMS do Estado do Rio de Janeiro. A hipótese a ser testada no trabalho é com base na elasticidade, qual o setor em que o governo deveria ter seus investimentos priorizados a fim de otimizar a arrecadação total. O período de análise compreende os anos de 1997 a 2019. Optou-se por esse período, por compreender momentos de grandes investimentos públicos e 
privados, decorrentes dos eventos internacionais, Copa do Mundo Fifa 2014 e Olimpíadas de 2016, bem como, a crise financeira em que passa o Rio de Janeiro.

O artigo está assim dividido: na segunda seção, discutem-se os conceitos e a metodologia para se obter as elasticidades da receita tributária; na terceira, analisa-se a evolução da arrecadação do ICMS do Estado do Rio de Janeiro ao longo do período por setor analisado; na quarta expõe-se os resultados das estimações das elasticidades dos diversos setores na arrecadação total de ICMS; na quinta e última, tecem-se as considerações finais.

\section{Conceitos e a metodologia utilizada para obter as elasticidades da receita tributária}

\subsection{Imposto sobre operações relativas à circulação de mercadorias e sobre prestação de serviços (ICMS)}

A tributação é um fenômeno intersistêmico que, segundo Benegas e Alves (2014), envolve a política, a economia e o direito.

\footnotetext{
"No caso da política, a tributação pode ser vista como uma relação entre poder e não poder tributar, ou seja, exigir prestações pecuniárias compulsórias de particulares; no caso da economia, pode ser entendida como um elemento relativo à programação dos agentes econômicos sobre o que terão ou não nas situações de produção, acumulação e circulação de bens em uma dada sociedade; o direito, por sua vez, considera a tributação como um conjunto de expectativas institucionalizadas que preveem como os agentes devem se comportar nas relações entre o poder de tributar e as limitações a este poder, determinando as sanções pelo descumprimento dessas normas condicionais. (Benegas e Alves, p.62, 2014).
}

O imposto sobre operações relativas à circulação de mercadorias e sobre prestação de serviços (ICMS) tem como fato gerador as operações relativas à circulação de mercadorias e à prestação de serviços de transporte interestadual e intermunicipal e de comunicações, ainda que as operações e as prestações se iniciem no exterior, de acordo com o capítulo 1 , Art. $1^{\circ}$ da Lei Estadual no 2.657, de 26 de dezembro de 1996 (Secretaria de Fazenda do Estado do Rio de Janeiro, 1996). O ICMS é o principal imposto de competência dos estados (Adaptado de: BACEN, 2019). 
De acordo com Lukic (2017), o Imposto sobre Circulação de Mercadorias (ICM), agora ICMS, nasceu na reforma tributária promovida pela Emenda Constitucional (EC) em 1965, em substituição ao Imposto sobre Vendas e Consignações (IVC) e na tentativa de implementar um sistema moderno de tributação sobre o valor adicionado no Brasil.

No Brasil, o principal tributo indireto com incidência sobre o consumo é o Imposto sobre operações relativas à circulação de mercadorias e serviços de transporte interestadual e intermunicipal e de comunicações (ICMS) (Politi e Mattos (2012)).

\section{Gráfico 1 - Receita Realizada Acumulada (em milhões de R\$)}

\section{Posição 10/2019 - Total R\$41.198.164.029,57}
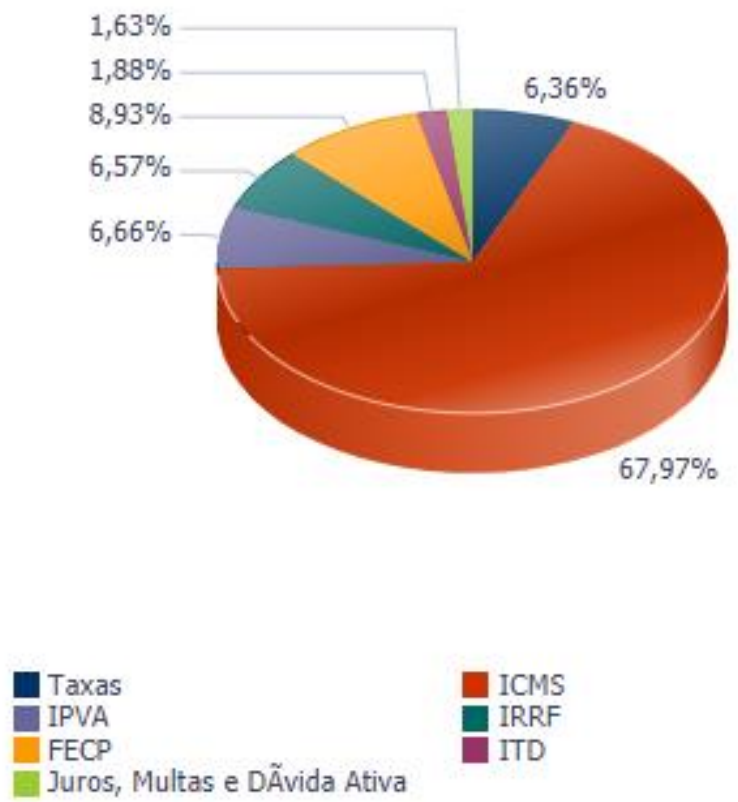

Fonte: Sistema Integrado de Gestão Orçamentária, Financeira e Contábil do Rio de Janeiro (SIAFE-Rio), em $12 / 10 / 2019$

O gráfico 1 mostra a distribuição da receita realizada acumulada dos diferentes impostos e taxas do Estado do RJ, com posição de outubro de 2019. Como pode ser visto, o ICMS responde por $67,97 \%$ de toda a receita do Governo do Estado do Rio de Janeiro.

O ICMS, de acordo com Amaral (2004), se utiliza do método do crédito fiscal, que funciona da seguinte forma: ao total das vendas feitas no estágio t aplica-se a alíquota do imposto, e se reduz desse resultado total do imposto equivalente ao total das compras também executadas no estágio t (que funciona como um crédito). Conforme explicado por Varsano (1997), a Constituição de 1988 introduziu importantes alterações neste tributo que é a principal fonte de 
receita dos estados brasileiros. Primeiro, aproximou-o do conceito teórico de imposto sobre o valor adicionado (IVA), ao estabelecer que todos os insumos produtivos gerarão crédito do imposto pago anteriormente pelo adquirente. Segundo, assemelhou o ICMS - que era um IVA tipo produto bruto - a um IVA tipo consumo, ao permitir que os contribuintes se creditem do imposto pago sobre bens que incorporarem a seus ativos permanentes.

\subsection{Elasticidade}

De acordo com Baye (2010), a elasticidade mede o efeito de mudanças em uma variável sobre outra variável. Ela é uma ferramenta básica para determinar a magnitude dessa mudança, ou seja, qual o percentual de variação na variável 2, dada a variação na variável 1 .

O autor ainda explica que o sinal da elasticidade determina a relação entre essas variáveis. Se a elasticidade é positiva, um aumento na variável 1 leva a aumento variável 2 . Se a elasticidade é negativa, um aumento na variável 1 levará a uma diminuição na variável 2.

O conceito de elasticidade é bastante utilizado por economistas e por formuladores de políticas públicas. Neste artigo, busca-se identificar o setor que tendo sua receita de ICMS aumentada gera maior percentual de aumento na receita total de ICMS do Estado do RJ. Conhecendo o setor que corresponde pela maior fatia de arrecadação, permite que sejam desenvolvidas, políticas que contribuam para que a arrecadação nesse setor continue crescente.

\subsection{Setores da Economia}

Esse artigo irá analisar as receitas de ICMS do Estado do RJ por segmento de atividade. As informações estão divididas em 5 (cinco) segmentos: setor primário, setor secundário, setor terciário, setor de energia, setor de petróleo, e demais fontes. Os setores de energia e petróleo estão sendo analisados de forma independente devido às suas relevâncias no total arrecadado. A soma dos segmentos corresponde ao total do ICMS arrecadado pelo Estado.

A economia moderna é formada por um conjunto complexo de atividades econômicas, que formam uma imensa teia de relações na produção de todos os bens e serviços destinados as necessidades que existem na sociedade (Pereira, Lopes e Pontini (2011)). De acordo com Rossetti (1990) $e$ (Pereira, Lopes e Pontini (2011)), devido à grande complexidade do sistema se torna inviável contabilizar individualmente cada operação realizada. Para se realizar essas operações contabilmente é necessário separar a economia em setores de atividade que se juntam devido as suas semelhanças e às atividades as quais se destinam. Assim, de modo 
clássico, as economias são subdivididas em três grandes setores de produção, sendo eles o setor primário, o setor secundário e o setor terciário (agricultura, indústria e comércio).

O setor primário (Pena, 2019) refere-se à extração de recursos da natureza e sua transformação em matérias-primas para a indústria. As atividades englobadas pelo Setor Primário são a agricultura, a pecuária e o extrativismo vegetal, animal e mineral.

Nos países desenvolvidos e em alguns emergentes, o setor primário é sobreposto pelo secundário e, principalmente, pelo terciário. Já nos países e regiões menos desenvolvidas, as atividades ligadas à agropecuária e ao extrativismo são consideradas ainda as principais fontes de manutenção econômica. Apesar de fundamental, a produção de matérias-primas não gera muita riqueza para os países com economias baseadas neste setor, pois estes produtos possuem baixo valor agregado.

O setor secundário é o responsável pela transformação dos recursos provenientes do setor primário, como as indústrias e a construção. Através desse processo são gerados os produtos industrializados com a finalidade de atender à necessidade humana, como roupas, eletrônicos, casas, carros e até mesmo máquinas e ferramentas industriais.

Fazem parte deste setor, entre outras, as indústrias automobilísticas, alimentícias, de tecnologia e informática, e a construção civil.

De acordo com Pereira, Lopes e Pontini (2011), o setor secundário refere-se às indústrias de transformação e de construção. Gomes e Barbieri (2014) definem este setor como um setor que gera riqueza considerável e base para o desenvolvimento dos países com atuação forte nesse setor. Porém, é também o responsável por grande parte da poluição e degradação do planeta.

O setor terciário é também conhecido como o setor de serviços. O crescimento dos serviços é uma característica básica do desenvolvimento das economias capitalistas centrais na segunda metade do século XX, de acordo com Pereira (2012). De acordo com Kon (2004) apud Pereira (2012), o termo terciário foi introduzido por Fischer em 1935 e a divisão das atividades em três setores (primário, secundário e terciário) foi sugerida por Colin Clark em 1940, o qual adotou o termo "residual" para o setor terciário, ou seja, somente após a mensuração dos outros setores, seria encontrado, por resíduo, o valor do setor terciário. 


\subsection{Descrição dos dados e metodologia utilizada}

Foram analisados os dados mensais de arrecadação de ICMS no estado do Rio de Janeiro, do período de janeiro de 1997 a abril de 2019. Os dados foram extraídos do site do Banco Central do Brasil e as séries mensais utilizadas neste estudo, encontram-se descritas, conforme tabela1 abaixo:

Tabela 1 - Séries mensais - Arrecadação ICMS - Rio de Janeiro

\begin{tabular}{lcl}
\hline Série ${ }^{\text {o }}$ & Variável & Descrição \\
\hline 4344 & Itotal & Receita dos estados e municípios (Fluxos) - Arrecadação de ICMS - Rio de Janeiro total \\
7641 & $X 1$ & Arrecadação de ICMS (Fluxos) - Setor primário - Rio de Janeiro \\
7652 & $X 2$ & Arrecadação de ICMS (Fluxos) - Setor secundário - Rio de Janeiro \\
7663 & $X 3$ & Arrecadação de ICMS (Fluxos) - Setor terciário - Rio de Janeiro \\
7674 & $X 4$ & Arrecadação de ICMS (Fluxos) - Energia - Rio de Janeiro \\
7685 & $X 5$ & Arrecadação de ICMS (Fluxos) - Petróleo - Rio de Janeiro \\
7696 & $X 6$ & Arrecadação de ICMS (Fluxos) - Outras fontes - Rio de Janeiro \\
\hline
\end{tabular}

Fonte: Elaboração própria com base nos dados disponíveis no Banco Central do Brasil

Foi utilizado o método de regressão linear para obter a elasticidade da receita tributária das séries em estudo. Conforme Gujarati (2011), a análise de regressão se refere ao estudo da dependência de uma variável, a variável dependente, em relação a uma ou mais variáveis explanatórias, com o objetivo de estimar e/ou prever o valor médio, da população, da primeira com base nos valores conhecidos ou fixados das segundas.

Com isso, buscou-se verificar como a arrecadação total de ICMS no estado do Rio de Janeiro se relaciona com a arrecadação desse imposto nos setores primário, secundário, terciário, energia, petróleo e outros, isto é, a variação percentual da arrecadação do ICMS total em resposta a uma variação de $1 \%$ na arrecadação de ICMS dos setores em estudo. Para testar a sensibilidade da receita tributária, utilizou-se o seguinte modelo estático, conforme equação 1:

$$
\begin{aligned}
\ln (\text { Itot }) t= & \beta 0+\beta 1 \ln (X 1) t+\beta 2 \ln (X 2) t+\beta 3 \ln (X 3) t+\beta 4 \ln (X 4) t \\
& +\beta 5 \ln (X 5) t+\beta 6 \ln (X 6) t+E_{t}
\end{aligned}
$$

O modelo econométrico considerou a receita dos estados e municípios (Fluxos) Arrecadação de ICMS - Rio de Janeiro (Itot) como variável dependente e as variáveis $X_{1}$ a $X 6$ como explicativas. O termo de erro (Et) representa todas as variáveis omitidas no modelo, mas que coletivamente afetam a variável dependente Itot. De acordo com Gujarati (2011), em 
um modelo de regressão múltipla, não é fácil determinar a relação funcional adequada e o termo do erro estocástico assume papel fundamental na análise de regressão.

Previamente as análises realizadas, o modelo foi submetido ao teste de heterocedasticidadeda para verificar variância dos erros. Conforme tabela 2 foi detectada a presença de homocedasticidade, o que demonstra a consistência do modelo e eficiência dos parâmetros analisados.

Quando consideramos a suposição de homoscedasticidade, variância constante dos erros, segundo o Teorema de Gauss-Markov, o estimador da matriz de covariância de B possui variância mínima, ou seja, apresenta as melhores estimativas entre todos os possíveis estimadores do parâmetro desconhecido, é eficiente e não viesado (Souza, 2015).

Tabela 2: Teste de Heterocedasticidade (ARCH)

\begin{tabular}{lcll}
\hline F-statistic & 0.171710 & Prob. F(1,265) & 0.6789 \\
Obs*R-square & 0.172894 & Prob. Chi-Square (1) & 0.6776 \\
\hline
\end{tabular}

Fonte: Elaboração própria com base nos dados disponíveis no Banco Central do Brasil

De acordo com Gujarati (2011), dadas as premissas do modelo clássico de regressão linear, para atender o teorema de Gauss-Markov, precisamos considerar a propriedade de melhor estimador linear não viesado, ou não tendencioso. Um estimador é considerado o melhor estimador não viesado, se atender as seguintes condições:

1. É linear nos parâmetros;

2. É não viesado, ou não tendencioso;

3. Tem variância mínima na classe de todos os estimadores lineares não viesados, sendo que um estimador não viesado com a menor variância é conhecido como estimador eficiente. 


\section{A evolução da arrecadação do ICMS no Estado do Rio de Janeiro}

Conforme metodologia adotada, foram analisados os dados mensais de arrecadação de ICMS dos diversos setores no estado do Rio de Janeiro, do período de janeiro de 1997 a abril de 2019.

Gráfico 2 - Evolução histórica da arrecadação de ICMS no RJ

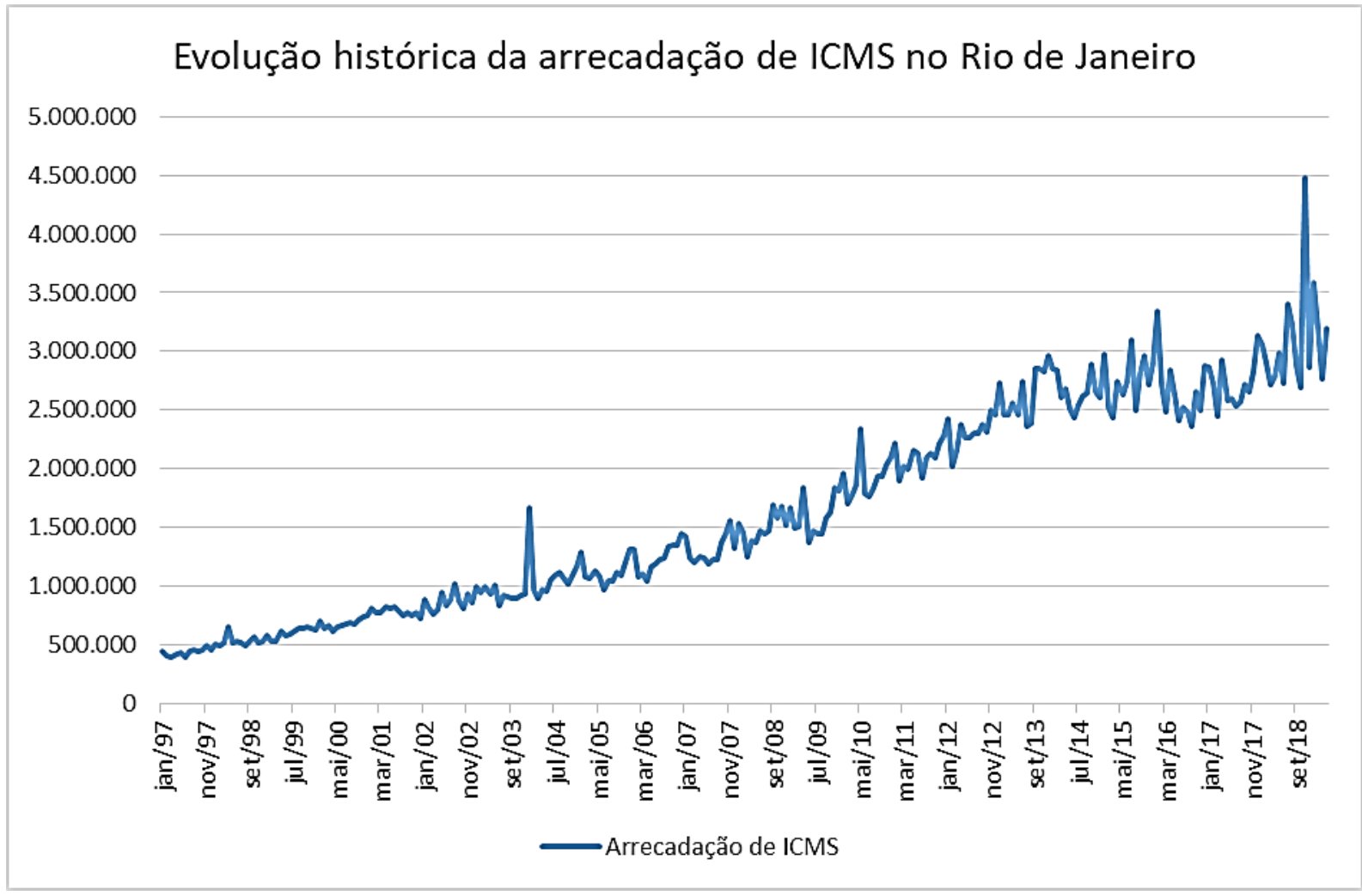

Fonte: Elaboração própria com base nos dados disponíveis no Banco Central do Brasil

No gráfico 2, apresenta-se a evolução da arrecadação total de ICMS no estado do Rio de Janeiro. Nota-se que uma aceleração na tendência de crescimento a partir de 2009 e uma redução no ritmo de elevação de arrecadação a partir de 2013. 


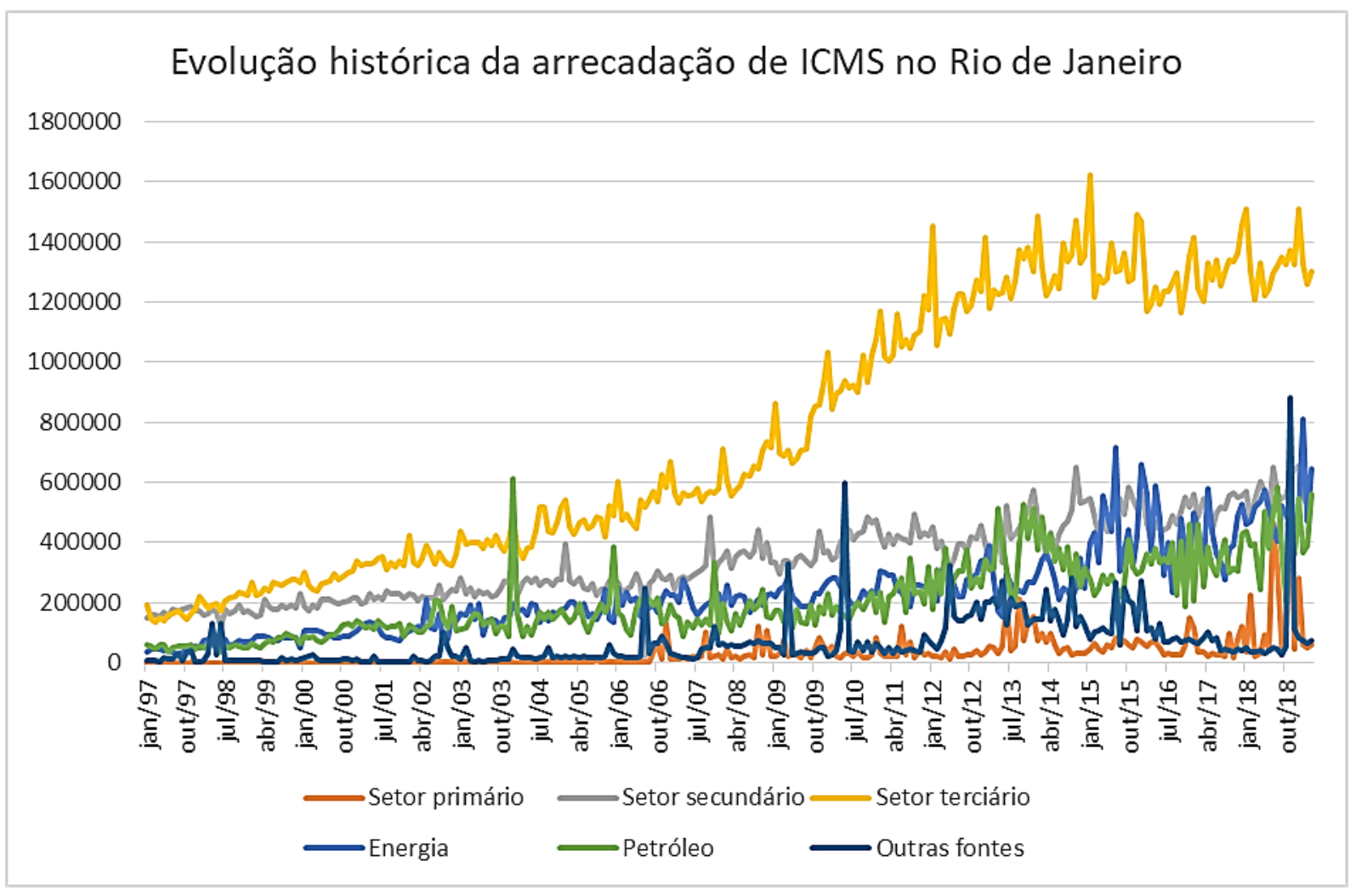

Fonte: Elaboração própria com base nos dados disponíveis no Banco Central do Brasil

No gráfico 3, apresenta-se a evolução segregada pelos setores econômicos fluminense. Assim como na arrecadação total de ICMS, observa-se uma grande elevação da taxa de crescimento da arrecadação do setor terciário a partir de 2009 e uma estagnação a partir de 2013. Destacase também a relevante evolução na arrecadação do setor de energia e a estagnação do setor primário no período analisado.

\section{Resultados}

Considerando a metodologia já anteriormente descrita, a regressão múltipla utilizada buscou estimar os parâmetros de cada setor, indicando assim a elasticidade dos setores na arrecadação total de ICMS do estado do Rio de Janeiro.

Em função do modelo econométrico considerar todas as variáveis que impactam na variável dependente, as estatísticas da regressão apresentaram um elevado R-Quadrado conforme demonstrado na tabela 3 abaixo: 
Tabela 3 - Estatística de Regressão

\begin{tabular}{lr}
\hline \multicolumn{2}{c}{ Estatística de regressão } \\
\hline R múltiplo & 0,999990777 \\
R-Quadrado & 0,999981554 \\
R-quadrado ajustado & 0,996164408 \\
Erro padrão & 0,061488249 \\
Observações & 268 \\
\hline
\end{tabular}

Fonte: Elaboração própria com base nos dados disponíveis no Banco Central do Brasil

De acordo com a Tabela 4 abaixo, além de um R-Quadrado elevado, a regressão também apresentou alta significância.

Tabela 4 - ANOVA

\begin{tabular}{|c|c|c|c|c|c|}
\hline & $g l$ & $S Q$ & $M Q$ & $F$ & F de significação \\
\hline Regressão & 6 & 53699,59 & 8949,93 & 2367202,85 & 0 \\
\hline Resíduo & 262 & 0,99 & 0,00 & & \\
\hline Total & 268 & 53700,58 & & & \\
\hline
\end{tabular}

Fonte: Elaboração própria com base nos dados disponíveis no Banco Central do Brasil

Além dos resultados estatísticos apresentados, foram estimados os parâmetros de cada setor conforme tabela abaixo:

Tabela 5 - Estimação de Parâmetros de Cada Setor

\begin{tabular}{ccccc}
\hline & Coeficientes & Erro padrão & Stat t & valor-P \\
\hline Intersecção & 0 & \#N/D & \#N/D & \#N/D \\
\hline$X 1$ & $-0,026894151$ & 0,003164 & $-8,49907$ & $1,46569 \mathrm{E}-15$ \\
$X 2$ & 0,303568038 & 0,014582 & 20,81752 & $1,82517 \mathrm{E}-57$ \\
$X 3$ & 0,487921891 & 0,022853 & 21,3503 & $2,80719 \mathrm{E}-59$ \\
$X 4$ & 0,137104723 & 0,013872 & 9,883869 & $8,74628 \mathrm{E}-20$ \\
$X 5$ & 0,152651717 & 0,013319 & 11,46129 & $6,41357 \mathrm{E}-25$ \\
$X 6$ & 0,050750037 & 0,004744 & 10,69785 & $2,12795 \mathrm{E}-22$ \\
\hline
\end{tabular}

Fonte: Elaboração própria com base nos dados disponíveis no Banco Central do Brasil 
Os resultados observados revelam que todas as variáveis são relevantes para o modelo econométrico proposto. Considerando os coeficientes estimados a equação 1 assume o seguinte formato:

$$
\begin{aligned}
\ln (\text { Itot }) t= & -0,026894151 \ln (X 1) t+0,303568038 \ln (X 2) t \\
& +0,487921891 \ln (X 3) t+0,137104723 \ln (X 4) t \\
& +0,152651717 \ln (X 5) t+0,050750037 \ln (X 6) t
\end{aligned}
$$

De acordo com os coeficientes estimados, o setor terciário, representado pela variável $X 3$, é o que apresenta a maior elasticidade dos setores analisados. $\mathrm{O}$ coeficiente elasticidade de 0,48 deste setor significa que o aumento de $1 \%$ na arrecadação do setor terciário gera um aumento de $0,48 \%$ da receita de ICMS total. Já uma queda de $1 \%$ na variável 3 é acompanhada de uma redução de $0,48 \%$ da receita total de ICMS.

Todos os demais setores, com exceção do setor primário, apresentaram elasticidades positivas, o que significa dizer que o aumento da arrecadação de ICMS do setor tende a elevar a arrecadação total.

Os resultados indicam que todos os setores, com exceção do setor primário, contribuem positivamente com a arrecadação total de ICMS do estado fluminense. Porém, a arrecadação do setor terciário apresentou elasticidade superior aos demais setores, ao longo do período em análise, o que reflete a relevância desse setor na economia regional, sendo, portanto, o setor sugerido a ser priorizado para investimentos, a fim de otimizar da arrecadação fiscal do estado.

\section{Considerações Finais}

Este trabalho procurou analisar a evolução da arrecadação do Imposto de Circulação de Mercadorias e Serviços (ICMS) do Estado do Rio de Janeiro no período de 1997 a 2019 e identificar qual o setor da economia fluminense deveria ser priorizado para otimizar a arrecadação total desse imposto no estado, com base na estimação da elasticidade da receita tributária.

Optou-se por compreender momentos de grandes investimentos públicos e privados, decorrentes dos eventos internacionais, Copa do Mundo Fifa 2014 e Olimpíadas de 2016, bem como, a crise fiscal e financeira que passa o Rio de Janeiro. 
Diante dos recentes escândalos de corrupção envolvendo a Petrobras, muitos artigos jornalísticos noticiaram os impactos negativos no Rio de Janeiro em função da alta relevância do setor de petróleo para a economia fluminense, sendo considerado por muitos o mais importante para o estado. Porém, apesar da retração econômica verificada até hoje, pelos resultados apresentados, o setor mais relevante para o estado do Rio de Janeiro é o setor terciário, seguido do setor secundário.

Zuccolotto, Ribeiro e Abrantes (2009) observaram que uma alternativa para solucionar o problema de déficits na arrecadação é expandir seu potencial, a fim de que não fiquem tão dependentes de outras esferas do Governo.

De acordo com Marques Jr. e Oliveira (2014), a sensibilidade da receita tributária visa auxiliar a tomada de decisão na condução da política fiscal e planejamento das contas públicas, o que corrobora com a análise realizada neste estudo.

O presente trabalho indica que todos os setores analisados, com exceção do setor primário, apresentaram elasticidades positivas, o que significa dizer que o aumento da arrecadação de ICMS desses setores tende a elevar a sua arrecadação total.

Porém, a arrecadação do setor terciário apresentou elasticidade superior aos demais setores ao longo do período em análise, o que reflete a relevância desse setor na economia regional e serve como balizador para que o governo do estado do Rio de Janeiro priorize esse setor de modo a otimizar os investimentos e maximizar a arrecadação total de ICMS.

\section{REFERÊNCIAS}

AMARAL, Rafael Gãneme. Tributação ao álcool combustível no Brasil. Rio de Janeiro: PUC, 2004. P. 05 - 42. Dissertação de Graduação, Pontifica Universidade Católica do Rio de Janeiro, Departamento de Economia.

Banco Central do Brasil (BACEN). Base de arrecadação de ICMS. Disponível em: $<$ https://www3.bcb.gov.br/sgspub/localizarseries/localizarSeries.do?method=prepararTelaLoc alizarSeries> Acesso em: 13 out 2019.

BAYE, Michael. R. Economia de Empresas e Estratégias de Negócios. Porto Alegre: Mc Graw Hill, 2010. P. 74 - 109. 
BENEGAS, Mauricio e ALVES, Lúcio Flavio. Uma análise sobre efeito final do ICMS e o IRPF na distribuição de renda do Estado do Ceará. Planejamento de Políticas Públicas. Ipea, Ceará, v. 43, p. 61 - 89, jul/dez.2014.

Federação de Indústrias do Estado (FIRJAN). Pesquisas e Estudos Socioeconômicos. Disponível em: < www.firjan.com.br/publicacoes> Acesso em: 13 out 2019.

GOMES, Jesus de Lisboa e BARBIERI, José Carlos Gerenciamento de recursos híbridos no Brasil e no Estado de São Paulo: um novo modelo de política pública. Fundação Getúlio Vargas, Rio de Janeiro, v.II, nº 3, p. 1 - 21, dezembro 2004.

GUJARATI, Damonar. N e POTER, Dawn. C. Econometria básica. Porto Alegre: Mc Graw Hill, 2011. P. $62-69$.

KON, Anita. Economia de serviços: teoria e evolução no Brasil: inclui uma análise sobre o impacto do setor de serviços no desenvolvimento econômico. Rio de Janeiro: Elsevier, 2004. P. 1 - 260.

LUKIC, Melina Souza Rocha. Tributação no Brasil: estudos, ideias e propostas: ICMS, seguridade social, carga tributária, impactos econômicos. Brasília: Ipea, 2017. P. 31 - 64.

MARQUES JUNIOR, Liderau dos Santos e OLIVEIRA, Cristiano Aguiar. As elasticidades de curto e longo prazo do ICMS no RS. Porto Alegre: Fundação de Economia e Estatística, 2014. P. 4 -14.

MINISTÉRIO DA ECONOMIA, 2019. Disponível em:

< http://www.in.gov.br/web/dou/-/resolucao-n-16-de-1-de-abril-de-2019-173019931> Acesso em: 22 out 2019.

PENA, Rodolfo F. Alves. Setor Primário da Economia. Disponível em:

$<$ https://mundoeducacao.bol.uol.com.br/geografia/setor-primario-economia.htm>Acesso em 22 out 2019.

PEREIRA, Luiz Carlos Bresser Pereira. O Crescimento Perverso dos Serviços, Resultado da Estagnação Industrial. Jornal da Tarde, 16 de junho de 1989. Disponível em:

<http://www.bresserpereira.org.br/Articles/1989/927.Crescimento_Perverso_dos_Servi\%C3\% A7os.pdf> Acesso em: 31/10/2019.

PEREIRA, Marcio Zanelli. Interação do setor de serviços com os demais setores da economia: uma análise de insumo produto (2000-2005). Juiz de Fora: Universidade Federal de Juiz de Fora, 2012. P. 13 - 96. Dissertação de Mestrado em Economia Aplicada. 
PEREIRA, Mirian Tomiato; LOPES, Janete Leige e PONTILI, Rosangela Maria. Renda, escolaridade e gênero dos trabalhadores formais inseridos no setor de serviços de Campo Mourão. Paraná: II Seminário dos Cursos de Ciências Sociais Aplicadas da Fecilcam, 2011.

POLITI, Ricardo Batista e MATTOS Enilnson Henrique Carvalho de. Uma nota sobre estimativas de carga fiscal e incidência de ICMS usando dados em painel. Fundação Getúlio Vargas, Rio de Janeiro, p. 361 -374, Jul/Set/2012.

ROSSETTI, Jose Paschoal. Contabilidade Social. São Paulo: Atlas, 1990.

SECRETARIA DE FAZENDA DO ESTADO DO RIO DE JANEIRO (Siafe), 2019. Disponível em:

<http://www.fazenda.rj.gov.br/sefaz/faces/oracle/webcenter/portalapp/pages/navigationrenderer.jspx?_afrLoop=1772746305882363\&datasource $=$ UCMServer\%23dDocName\%3A9 8875\&_adf.ctrl-state=ru3kbvue3_63> Acesso em: 30/10/2019.

SOARES, Maurélio, GOMES, Ely do Carmo Oliveira e TOLEDO FILHO, Jorge Ribeiro. A repartição tributária dos recursos do ICMS nos municípios da Região Metropolitana de Curitba. Revista de Administração Pública. Rio de Janeiro, p. 459 - 481, Mar/Abr/2011.

SOBRAL, Bruno Leonardo Barth. A Crise no Estado do Rio de Janeiro Entendida Não Apenas Como Uma Questão Financeira. Geo UERJ. Rio de Janeiro, p. 34 - 63, 2017.

SOUZA, Saul de Azevedo. Comparação dos Estimadores Robustos e de Mínimos Quadrados Ordinários. João Pessoa: UFPB, 2015. P. 1 - 43. 2015. Dissertação de Graduação, Universidade Federal da Paraíba, Departamento de Estatística.

VARSANO, Ricardo. A guerra fiscal do ICMS: quem ganha e quem perde. Ipea. Rio de Janeiro, no 15, p. 3 - 19, 1997.

ZUCCOLOTTO, Robson; RIBEIRO, Clarice Pereira de Paiva. e ABRANTES, Luiz Antônio. O comportamento das finanças públicas municipais nas capitais dos estados brasileiros de custos. Enfoque Reflexão Contábil. Vitória, 28, n. 1, p. 54-69, 2009. 